\title{
A comparative study of endoscopic findings, Rapid Urease Test and Conventional Histopathology in diagnosis of Helicobacter Pylori infection
}

\author{
Adlekha S. ${ }^{1}$, Chadha T. ${ }^{2}$ \\ ${ }^{1}$ Dr Shashikant Adlekha, Department of Pathology; ${ }^{2}$ Dr Tandra Chadha, Department of Microbiology, both authors are \\ attached with, Maharaja Institute of Medical Sciences, Vizianagram, Andhra Pradesh, India.
}

Address for Correspondence: Dr Tandra Chadha, Maharaja Institute of Medical Sciences, Vizianagram, Andhra Pradesh, India, Email: ruc.isha@gmail.com

\begin{abstract}
Background: Helicobacter pylori (H pylori) related gastritis is a major health ailment in developing nations. There is high morbidity and mortality ranging from chronic gastritis to gastric malignancies. Prevalence of $H$ pylori infection varies markedly from country to country and in a country, region to region. Aim of the study: To evaluate the commonly available diagnostic methods, Rapid Urease Test (RUT) and conventional histopathology in diagnosis of $H$ pylori gastritis and analyse the association of $\mathrm{H}$ Pylori with the development of gastrointestinal complications. Settings and design: Cross sectional prospective study conducted during the period of May 2012 to September 2014. Material and method: The study was carried out in a tertiary medical college hospital in southern India. Patients presenting with dyspeptic symptoms were subjected to endoscopy and investigated for $H$ pylori infection through histopathological examination and RUT of biopsy specimen. Diagnosis of $\mathrm{H}$ pylori was made if one or both diagnostic test results were positive. Results: Out of 530 patients analyzed, diagnosis of $H$ pylori was made in 329 patients $(62.0 \%)$. There were significant statistical correlations of presence of endoscopic abnormalities and serious gastrointestinal complication (peptic ulcer and dysplasia/cancer) with H pylori infection. RUT had comparable predictive values to histopathology in diagnosis of $H$ Pylori infection. Conclusion: H Pylori is implicated with significant morbidity and mortality due to associated gastrointestinal complications. Early and precise detection by multiple cost-effective methods, bearing good patient compliance and prompt treatment is essential for prevention of serious complications.
\end{abstract}

Keywords: H pylori infection, Histopathological examination, Rapid urease test, Gastrointestinal complications

\section{Introduction}

Chronic gastritis and gastric ulceration are prevalent in a high magnitude throughout the world [1]. H pylori gastritis is the principal cause of chronic active gastritis and has major complications like gastric adenocarcinoma and mucosa associated lymphoid tissue lymphoma (MALT lymphoma) [2]. H pylori is a Gram negative flagellated bacilli that usually colonizes gastric pits under the mucus layer and in close association to gastric epithelial cells. Approximately $50 \%$ of normal population across the world harbour $H$ pylori, though only $10-20 \%$ of them become symptomatic $[3,4]$. There is association of $\mathrm{H}$ pylori infection with the hygiene

Manuscript received: $20^{\text {th }}$ June 2017

Reviewed: $1^{\text {st July } 2017}$

Author Corrected: $11^{\text {th }}$ July 2017

Accepted for Publication: 18 $8^{\text {th }}$ July 2017 related conditions, life style and economy with annual incidence rate of $H$ pylori infection $\approx 4-5 \%$ in developing nations compared to that of $\approx 0.5 \%$ in developed and industrialized countries [5].

There are many other etiological factors such as smoking, non steroidal antiinflammatory drugs (NSAIDS), reflux of gastric juice (chemical gastritis) that are also implicated to cause chronic gastritis. $H$ pylori, though is regarded as primary cause of gastritis, it can act as synergist in addition with other etiological factors [6].

A wide range of laboratory investigations are available for diagnosis of $H$ pylori. The tests belong to non 
Research Article

invasive group and invasive group. Non invasive tests include urea breath test (UBT), serological $\operatorname{IgG}$ and IgM detection, saliva and urinary antibody test and stool antigen test [7]. The invasive tests are endoscopy based tests which include histopathological examination, RUT and polymerase chain reaction (PCR). Whereas invasive tests carry high sensitivity and specificity of $>90 \%$ [8], the role of non invasive tests such as serology is limited in areas of high prevalence, because of non distinction between previous and current infection. H. pylori infections like other major chronic infectious diseases (i.e., syphilis and tuberculosis) are associated with a long latent period before presenting clinically.

As such, many infections will be discovered during this latent period. A number of methods to $H$. pylori infection have been developed and they are generally grouped as being "invasive" meaning that they require gastric tissue or mucus, or "non-invasive" requiring only blood, breath or stool or analysis. Here, we discuss the rapid urease test (RUT) or RUT which is an invasive test in that it requires sampling of the gastric mucosa. The test provides indirect evidence of the infection by identifying the presence of a nonmammalian enzyme, urease, in or on the gastric mucosa. This study emphasized on finding out the predictive values of RUT and histopathology in detection of $H$ Pylori infection. Association of endoscopy related changes and gastrointestinal complications with $H$ Pylori infection was also computed.

\section{Methods}

Study design: Cross sectional prospective study conducted during the period of May 2012 to September 2014. Inclusion criteria: The patients were selected on the basis of chief complains of dyspepsia and the age of patients ranged from 14 to 86 years. Exclusion Criteria: Patients undergone proton pump inhibitor (PPI) therapy or any antibiotic therapy within last one month. Participants: The age of patients ranged from 14 to 86 years. Study Size: The study was conducted over 530 patients from out patients and in-patients.

Data analysis: Data analysis was done using statistical package for social sciences, version 16.0 (SPSS 16). Categorical variables were compared with Chi square test. $\mathrm{p}$ value $<0.05$ was taken as statistically significant. Endoscopy was carried out using "Pentax" forward viewing oesophago gastro duodenoscope. The endoscopy was considered normal on visualizing mucosa which is pink in colour, smooth and lustrous. Two endoscopic biopsy fragments were obtained from each patient from antrum. One biopsy fragment was sent to histopathology department in formalin container. Two sections of $4 \mu$ thickness were cut from each block and mounted on two slides, one each on a slide. Slides were stained with normal Haematoxylin and Eosin $(\mathrm{H}$ and E) stain and Giemsa stain. Histopathological assessment of gastric mucosa was done by pathologist and grading was done for mononuclear cell infiltration, neutrophilic infiltration, atrophy, intestinal metaplasia and density of $\mathrm{H}$ pylori according to the visual analogue of updated Sydney grading system [9] of reporting gastric biopsies. Microscopic assessment of slides was carried out using labomed microscope vision 2000, India. In positive cases, $H$ pylori appeared as light bluish rods in $\mathrm{H}$ and $\mathrm{E}$ stained slides with varying sizes (3-6 $\mu)$ on the luminal surface of mucosal cells.

In Giemsa stain, $\mathrm{H}$ pylori appeared dark blue in a light background. Another biopsy fragment was sent to microbiology department for RUT. RUT was performed by following method: Urea ( $2 \mathrm{~g}$ ) was dissolved in $20 \mathrm{ml}$ double distilled water. 20 drops of phenol red was added to the solution and $\mathrm{pH}$ was adjusted between 6.8 and 6.9 by adding a drop of $\mathrm{N} / 10 \mathrm{HCl}$, if $\mathrm{pH}$ was greater or $\mathrm{N} / 10 \mathrm{NaOH}$, if $\mathrm{pH}$ was less. Solution was faint yellow tint at this stage. This was transferred to sterile vial each containing $2 \mathrm{ml}$ in each vial. Biopsy material was added and the temperature was kept constant at $35-37^{\circ} \mathrm{C}$. Test was considered positive, if colour changed within 30 minutes and weekly positive, if the change occurred after 2 hours.

The study was approved by scientific research committee of the institution. The study involved the data analysis of routine procedure carried out in institution and informed consent was obtained from each patient before the procedure. Positivity for one or more methods- histopathology by any of the stains (H\&E/Giemsa) or RUT was considered as true positive. Sensitivity, specificity, PPV and NPV of different methods were computed and compared.

Sensitivity $=$ True positive/ $($ True positive + False negative); Specificity $=$ True negative $/$ (True negative + False positive); PPV = True positive/ (True positive + False positive); NPV = True negative/ (True negative + False negative). Youden's index = Sensitivity + Specificity -100 . 


\section{Results}

Data of 530 patients were analyzed, out of which 328 (61.9\%) were males and 202 (38.1\%) were females. The mean age was $48.8 \pm 16.68$ years with age ranging from $14-86$ years. Histopathological examination showed $\mathrm{H}$ pylori positivity in 315 cases and rapid urease test showed $\mathrm{H}$ pylori positivity in 306 cases. Diagnosis of $\mathrm{H}$ pylori infection was made if both or either of the tests was positive. 329 cases were found to be $H$ pylori positive, on combining both test results.

Endoscopic abnormalities when compared with $H$ pylori presence, yielded significant results, with 294 out of 329 H pylori positive cases revealing any of the abnormalities, with p value $<0.001$ (Table 1). The most common endoscopic abnormality was gastritis $(69 \%)$, followed by duodenitis $(17 \%)$, oesophagitis $(12 \%)$, duodenogastric reflux $(7 \%)$, hiatal hernia (6\%) gastric ulcer (GU) (2\%), duodenal ulcer (DU) (2\%) and Barrett's oesophagus (2\%). Serious gastrointestinal pathology (GU, DU and carcinoma) was only seen in 42 patients (7.9\%). Patients showed varied presentation of clinical symptoms such as abdominal pain (61\%), gastric fullness (17\%), vomiting (12\%), fatty food intolerance (9\%), bloating (7\%), belching $(6 \%)$, melena $(5 \%)$, early satiety $(5 \%)$ and weight loss $(4 \%)$.

Table-1: Correlation of endoscopic abnormalities with $\mathrm{H}$ pylori infection:

\begin{tabular}{|c|c|c|c|c|}
\hline \multirow{2}{*}{\multicolumn{2}{|c|}{}} & \multicolumn{3}{|c|}{ Endoscopic abnormalities } \\
\cline { 3 - 5 } & & Present & Absent & Total \\
\hline \multirow{2}{*}{ H pylori } & Positive & $294(89.4 \%)$ & $35(10.6 \%)$ & $329(100 \%)$ \\
& Negative & $149(74.1 \%)$ & $52(25.9 \%)$ & $201(100 \%)$ \\
\hline
\end{tabular}

df-1, chi square-21.100, p-.000

Table-2: Types of histopathological reporting:

\begin{tabular}{|c|c|}
\hline Types of pathological reporting & \% Total biopsy cases examined \\
\hline H Pylori gastritis & $(329 / 530)$ \\
& $62.0 \%$ \\
\hline Reactive gastritis & $(56 / 530)$ \\
& $10.5 \%$ \\
\hline Non-specific gastritis & $(58 / 530)$ \\
& $10.9 \%$ \\
\hline Ulcer(Gastric, Duodenal) & $(21 / 530)$ \\
& $3.9 \%$ \\
\hline Dysplasia/carcinoma & $(21 / 530)$ \\
& $3.9 \%$ \\
\hline Normal gastric mucosa & $(45 / 530)$ \\
& $8.4 \%$ \\
\hline
\end{tabular}

Table-3: Categorisation of cases based on results of diagnostic tests

\begin{tabular}{|c|c|c|c|}
\hline Cases & Histopathology & RUT & Final result \\
\hline 292 & $\mathrm{P}$ & $\mathrm{P}$ & $\mathrm{P}$ \\
\hline 23 & $\mathrm{P}$ & $\mathrm{N}$ & $\mathrm{P}$ \\
\hline 14 & $\mathrm{~N}$ & $\mathrm{P}$ & $\mathrm{P}$ \\
\hline 201 & $\mathrm{~N}$ & $\mathrm{~N}$ & $\mathrm{~N}$ \\
\hline Total no. 530 & P- & P- $\mathbf{3 0 6 / 5 3 0}$ & $\mathbf{P - 3 2 9 / 5 3 0}$ \\
\hline
\end{tabular}

RUT-Rapid urease test, N-Negative, P-Positive, No.-Number 
Research Article

Table-4: Predictive value of different diagnostic tests

\begin{tabular}{|c|c|c|c|c|c|}
\hline Diagnostic methods & Sensitivity & Specificity & PPV & NPV & YI \\
\hline Histopathology & 95.7 & 100 & 100 & 93.4 & 95.7 \\
\hline RUT & 93.0 & 100 & 100 & 89.7 & 93.0 \\
\hline
\end{tabular}

RUT-Rapid urease test, PPV-Positive Predictive value, NPV-Negative predictive value, YI-Youden's index

Table-5: Pathological diagnosis and associated histopathological features.

\begin{tabular}{|c|c|c|c|c|c|}
\hline $\begin{array}{c}\text { Pathological } \\
\text { diagnosis }\end{array}$ & $\begin{array}{c}\text { H.Pylori\% } \\
\text { Positivity }\end{array}$ & $\begin{array}{c}\text { \% with acute } \\
\text { inflammation }\end{array}$ & $\begin{array}{c}\text { \% with chronic } \\
\text { inflammation }\end{array}$ & $\begin{array}{c}\text { \% with } \\
\text { intestinal } \\
\text { metaplasia }\end{array}$ & $\begin{array}{c}\text { \% with } \\
\text { glandular } \\
\text { atrophy }\end{array}$ \\
\hline $\begin{array}{c}\text { Gastritis } \\
(\mathrm{n}=443)\end{array}$ & $(292 / 443)$ & $(180 / 443)$ & $(359 / 443)$ & $(36 / 443)$ & $(83 / 443)$ \\
\hline Peptic ulcer & $(18 / 21)$ & $(21 / 21)$ & $(18 / 21)$ & $(7 / 21)$ & $(11 / 21)$ \\
$(\mathrm{n}=21)$ & $85.7 \%$ & $100 \%$ & $85.7 \%$ & $33.3 \%$ & $52.3 \%$ \\
\hline Dysplasia or cancer & $(19 / 21)$ & $(15 / 21)$ & $(17 / 21)$ & $(12 / 21)$ & $(15 / 21)$ \\
$(\mathrm{n}=21)$ & $90.5 \%$ & $71.4 \%$ & $80.9 \%$ & $57.1 \%$ & $71.4 \%$ \\
\hline
\end{tabular}

df-1, chi square-13.11, p-.000

Histopathological features when analyzed, 56 of 530 patients (10.5\%) were found to have reactive gastritis (Table 2). $H$ pylori positivity was seen in 292 of 443 patients $(65.9 \%$, Table 5) of patients with diagnosis of gastritis. Normal gastric mucosa was evident in 45 of 530 cases. Histological features such as intestinal metaplasia and glandular atrophy were seen in $8.1 \%$ and $18.7 \%$ respectively in patients with gastritis, whereas these entities were seen in $57.1 \%$ and $71.4 \%$ of cases respectively in patients with dysplasia/cancer. The correlation of gastrointestinal complications (Peptic ulcer and dysplasia/cancer) was statistically highly significant with $H$. pylori infection, with p value of $<0.001$, whereas correlation of gastritis with H pylori infection was statistically not significant, with $\mathrm{p}$ value of 0.092 .

\section{Discussion}

RUT is the most frequently performed test during routine gastroendoscopy practice. It is extremely valuable because it gives a positive result for $H$. pylori infection before the patient leaves the endoscopic suite. Histological diagnosis of $H$. pylori infection is usually reserved for patients with a negative biopsy urease test or when histology was required for another reason such as exclusion of malignancy. In an earlier study rapid urease test, said et al [10] had the sensitivity, specificity, positive predictive value, negative predictive value and diagnostic accuracy were $98 \%$, $100 \%, 100 \%, 98 \%$ and $99 \%$, respectively.

Gastritis, gastric ulceration and gastric malignancies have many etiological factors, among which $\mathrm{H}$ pylori infection is the principal cause. $\mathrm{H}$ pylori infection is dependent upon many variables such as age, sex, socioeconomic status, dietary habits, genetic and immunological factors. In the present study the commonest identifiable lesion at endoscopy was gastritis (69\%). The correlation of endoscopic abnormality with $\mathrm{H}$ pylori infection was statistically highly significant with a $\mathrm{p}$ value of $<0.001$, proving endoscopic changes to be a sensitive indicator of $\mathrm{H}$. pylori infection. This is in contrast to the observation laid by Jemilohun et al [11] in which the correlation was not statistically significant. This can be attributed to lower number of cases (86) being evaluated in their study compared to the present study (530).

Pathological reporting of 530 cases showed only (42/530) $7.2 \%$ of cases having serious gastrointestinal complications like peptic ulcers (GU and DU) and dysplasia/carcinoma. The association of these lesions with $H$. pylori infection was found to be statistically significant with 18 of $21(85.7 \%)$ patients with peptic ulcer and 19 of $21(90.5 \%)$ with dysplasia/carcinoma. Cotran et al [12] narrates the international association of $\mathrm{H}$ pylori with gastric ulceration to be more than $70 \%$. The present study showed $10.5 \%$ of cases having 
reactive gastritis. There is rising incidence of reactive gastritis in rural and suburban population of developing nations like India due to increased duodenogastric reflux associated with changing life style of the population, injudicious and rampant use of drugs like NSAID which are easily available and often being prescribed for musculoskeletal ailments.

The present study showed that dysplasia and carcinoma develop only in few of the cases having predisposing factors such as intestinal metaplasia and glandular atrophy. High H pylori prevalence, 19 of $21(90.5 \%)$ in cases having dysplasia and carcinoma in this study, implies that majority of gastric adenocarcinomas can be prevented with early stage detection of $H$. pylori and $H$ pylori eradication therapy.

This is in concordance with the findings documented by International agency for research on cancer, stating that $60 \%$ or more of gastric cancers worldwide can be prevented by absence of $H$ pylori infection [13].

As noted above, the RUT is a test for the presence of the urease enzyme. The actual results will however depend on the gastric disease and the likelihood of atrophic changes or exogenous factors that reduce the bacterial load and thus produce false negative results. False positive results can occur if other urease containing organisms are present in sufficient quantity or if one allows contact of the specimen and the media for a prolonged period, typically longer than 24 hours. Approximately $10^{5}$ bacteria must be present in the biopsy sample for a positive result [14].

The two most common reasons for false negative results are the recent use of proton pump inhibitors and the presence of intestinal metaplasia. It is unlikely that a false negative RUT will also be accompanied by histologically uninflamed and normal gastric mucosa. When in doubt and the result is important, it is best to obtain a noninvasive test (urea breath test or stool antigen) after discontinuation of the PPI.

False-positives are rare and when present may be due to the presence of other urease containing organisms such as Proteus mirabilis, Citrobactor freundii, Klebsiella pneumonia, Enterobactor cloacae and Staphylococcus aureus [15]. However unless the patient has achlorhydria or hypochlorhydria, non- $H$. pylori organisms are unlikely to be present in sufficient concentration to produce a positive test unless the RUT substrate lacks an inhibitor to bacterial growth in which they may possibly overgrow during the 24 hours observation period.

Generally speaking, upper endoscopy is an expensive test associated with a small but definite risk and unless there are specific contraindications, biopsy for examination of the mucosal histology is generally indicated. RUT testing can also be done and is especially helpful in difficult diagnostic situations when the physician would like to start treatment soon. The tissue sample contained in the agar of an RUT test can be used for molecular testing for $H$. pylori and/or for the presence of clarithromycin resistance

\section{Conclusion}

In conclusion there is high prevalence of $\mathrm{H}$ pylori infection in rural and suburban population of South India. Though the prevalence of $\mathrm{H}$. Pylori gastritis and associated abdominal symptoms is high in number, serious gastrointestinal complications develop in few. Absolute prevention of these complications and relief from the distressing abdominal symptoms can be achieved through early detection by conventional and affordable diagnostic methods and empirical treatment with anti $\mathrm{H}$ pylori therapy.

RUT should be used as an informal assessment of the accuracy of the pathology laboratory and discrepancies between the RUT and histology especially a positive RUT and negative histology should lead to prompt review of the histopathology. The positive tests, should be correlated with endoscopy findings and histological assessment of gastric mucosa should be done, where ever feasible, to gather additional information on architecture.

\section{Contribution}

Study concept, Data collection, Manuscript writing, Final review and approval- Dr Shashikant Adlekha Data collection, Data Compiling, Manuscript editing, Final review and approval- Dr Tandra Chadha.

Funding: Nil, Conflict of interest: None initiated, Permission from IRB: Yes

\section{References}

1. Ghazzawi IM, Obidat NA. The role of Helicobacter pylori infection in the pathogenesis of chronic urticaria. Pakistan J Med Sci 2004;20(2):101-4. 
2. Jhala NC, Siegal GP, Klemm K, Atkinson BF, Jhala DN. Infiltration of Helicobacter pylori in the gastric mucosa. Am J Clin Pathol. 2003 Jan;119(1):101-7.

3. Lacy BE, Rosemore J. Helicobacter pylori: ulcers and more: the beginning of an era. J Nutr. 2001 Oct; 131 (10):2789S-2793S.

4. Makola D, Peura DA, Crowe SE. Helicobacter pylori infection and related gastrointestinal diseases. J Clin Gastroenterol. 2007 Jul;41(6):548-58.

5. Duck WM, Sobel J, Pruckler JM, Song Q, Swerdlow $\mathrm{D}$, Friedman $\mathrm{C}$ et al. Antimicrobial resistance incidence and risk factors among Helicobacter pylori-infected persons, United States. Emerg Infect Dis 2004;10 (6): 1088-94.

6. Farooki JI, Farooki RJ. Non-steroidal antiinflammatory drugs induced gastrotoxicity. J Coll Physicians Surg Pak 2001;11:650-5.

7. Malfertheiner P, Megraud F, O'Morain C, Bazzoli F, El-Omar E, Graham D, Hunt R, Rokkas T, Vakil N, Kuipers EJ. Current concepts in the management of Helicobacter pylori infection: the Maastricht III Consensus Report. Gut. 2007 Jun;56(6):772-81.

8. Graham DY, Sung JY. Sleisenger and Fordtran's gastrointestinal and liver disease. pathophysiology, diagnosis, management. In: Feldman M, Friedman LS, Brandt LJ, editors. Helicobacter pylori. 7th ed. Philadelphia: WB Saunders Co; 2006. pp. 1049-66.

9. Dixon MF, Genta RM, Yardley JH, Correa P. Classification and grading of gastritis. The updated
Sydney System. International Workshop on the Histopathology of Gastritis, Houston 1994. Am J Surg Pathol. 1996 Oct;20(10):1161-81.

10. Said RM, Cheah PL, Chin SC, Goh KL. Evaluation of a new biopsy urease test: Pronto Dry, for the diagnosis of Helicobacter pylori infection. Eur $\mathbf{J}$ Gastroenterol Hepatol. 2004 Feb;16(2):195-9.

11. Jemilohun AC, Otegbayo JA, Ola SO, Oluwasola OA, Akere A. Prevalence of Helicobacter pylori among Nigerian patients with dyspepsia in Ibadan. Pan Afr Med J. 2010;6:18.

12. Cotran RS, Kumar V, Collins T. The gastro intestinal tract. In: Robbins pathologic basis of disease. 8thed. Philadelphia: WB Saunders;2010:763-831.

13. International Agency for Research on Cancer. Helicobacter pylori. In: IARC monograph on the evaluation of carcinogenic risks to humans. Vol. 61. Schistosomes, liver flukes and Helicobacter pylori. Lyon (France): International Agency for Research on Cancer; 1994. p. 177-240.

14. Mégraud F, Bessède E, Lehours P. Current methods used for the diagnosis of Helicobacter pylori infection. In: Buzás GM. eds. Helicobacter pylori - A Worldwide Perspective 2014. Oak Park: Bentham Science, 2014: 234-58.

15. Osaki T, Mabe K, Hanawa T, Kamiya S. Ureasepositive bacteria in the stomach induce a false-positive reaction in a urea breath test for diagnosis of Helicobacter pylori infection. J Med Microbiol. 2008; 57 (Pt 7):814-9. doi: 10.1099/jmm.0.47768-0.

\section{How to cite this article?}

Adlekha S, Chadha T. A comparative study of endoscopic findings, Rapid Urease Test and Conventional Histopathology in diagnosis of Helicobacter Pylori infection.Trop J Path Micro 2017;3(3):242-247.doi: 10.17511/jopm.2017.i3.02. 